\title{
The trefoil factor 1 (TFF1) protein involved in doxorubicin-induced apoptosis resistance is upregulated by estrogen in breast cancer cells
}

\author{
SONAM PELDEN, TONKLA INSAWANG, CHANITRA THUWAJIT and PETI THUWAJIT \\ Graduate Program in Immunology, Department of Immunology, Faculty of Medicine \\ Siriraj Hospital, Mahidol University, Bangkok 10700, Thailand
}

Received May 10, 2013; Accepted June 26, 2013

DOI: $10.3892 / 0 r .2013 .2593$

\begin{abstract}
Trefoil factor 1 (TFF1) is a small secretory protein expressed in various types of carcinomas including breast cancer. The TFF1 gene contains an estrogen response element and its expression can be regulated by estrogen. Previous reports showed that TFF1 could protect cells from induced apoptosis in vitro. In the present study, the effect of estrogen on the promotion of doxorubicin-induced apoptosis resistance and the role of TFF1 in this process was demonstrated using the MCF-7 breast cancer cell model. Stable knockdown of the TFF1 gene in MCF-7 cells was generated and used to test the sensitivity to doxorubicin treatment compared to mock control cells in the presence or absence of $17 \beta$-estradiol. The apoptotic cells were measured by flow cytometry. The results showed that with the stimulation of apoptosis by doxorubicin, $17 \beta$-estradiol could suppress this process in mock cells but not in TFF1 knockdown cells. Moreover, using a viable cell counting method, it was shown that the anti-TFF1 antibody could reverse the anti-apoptotic effect of estrogen in mock cells and recombinant TFF1 could recover doxorubicininduced cell death in TFFI knockdown cells. This process, however, could not be inhibited by fulvestrant, an estrogen antagonist. An apoptosis protein array experiment reflected the role of the anti-oxidative enzyme catalase in estrogen and TFF1-modulated apoptosis and this was confirmed by enzymatic assay. These phenomena determine the role of TFF1 in estrogen-promoted resistance to apoptosis induced by doxorubicin in MCF-7 breast cancer cells. The TFF1 gene may be a target for enhancing the sensitivity to chemotherapy in breast cancer treatment.
\end{abstract}

Correspondence to: Dr Peti Thuwajit, Graduate Program in Immunology, Department of Immunology, Faculty of Medicine Siriraj Hospital, 11th Floor Adulyadejvigrom Building, Mahidol University, Bangkok Noi, Bangkok 10700, Thailand

E-mail: petthu@msn.com; sipeti@mahidol.ac.th

Key words: apoptosis, trefoil factor 1 protein, breast cancer, estrogen, doxorubicin

\section{Introduction}

Breast cancer is the most common cancer in females worldwide with an age-standardized rate (ASR) of newly-diagnosed cases at 39/100,000 people and deaths at $12.5 / 100,000$ people annually, in 2008 (1). The incidence rate was reported as increasing, particularly in low- and middle-income countries (2). While the management of breast cancer has advanced from molecular studies to clinical outcome, the standard treatments for breast cancer are still based on surgery with improvement of tissue conserved, radiation and addition of chemotherapy both cytotoxic and targeted types, in the advance stages $(3,4)$. Breast cancer has a shown variety of cellular marker protein expressions which could determine responses to chemical treatment, for example, the estrogen receptor (ER), progesterone receptor (PR) and human epidermal growth factor receptor 2 (HER2), all of which may be considered as targets for effective therapies (5). ER indicated the response to estrogenic agents for regulation of cancer cell proliferation and this could be inhibited using anti-estrogenic drugs such as tamoxifen and fulvestrant which have been used in clinical practice (6). Moreover, in the past decades, there have been numerous reports of patients that demonstrated that expression of ER showed less sensitivity to cytotoxic agents in breast cancer cell (7-9). Recently, an in vitro experiment demonstrated the cellular response to co-treatment with estrogen and doxorubicin, a first-line cytotoxic chemotherapeutic agent commonly used in treatment of advanced stage breast cancer (10). It was shown that doxorubicin could impair estrogen-induced proliferation in human ER positive breast cancer cell lines T47D and MCF-7 (10). On the other hand, the role of estrogen in reducing the cytotoxic effect of doxorubicin cannot be undermined. The study of the mechanism of doxorubicin resistance in estrogenrelated ER positive breast cancer cells is also noteworthy.

Estrogen is a group of sex steroid hormones which functions mainly in the female reproductive system $(11,12)$. Traditionally, estrogen binds to intracellular ER and then the hormonereceptor complex should bind directly to the regulatory elements on DNA sequences, such as the estrogen responsive element (ERE), and affect gene expressions (11). These estrogen-regulated proteins are involved in several cellular processes including apoptosis (12). While the mechanism of 
almost all cytotoxic agents including doxorubicin is the induction of cancer cells to the apoptotic process resulting in cell death, the proteins that affect apoptosis should be considered as involved in drug resistance. In fact, estrogen could regulate breast cancer cells in opposite directions, apoptosis induction and anti-apoptosis, depending on various factors including estrogen concentration and cell types (12). Formerly, the treatment of ER positive breast cancer patients included the use of high-dose estrogen (13) until the use of anti-estrogen tamoxifen was implicated (14). With physiological concentrations of estrogen, the estrogen could stimulate apoptosis in MCF-7 cells with prolonged estrogen deprivation conditions (15). However, in physiological concentrations, estrogen prefers to inhibit apoptotic processes induced by serum deprivation in ER positive breast cancer cell lines MCF-7, T47D and ZR-75-1 (16). In addition, estrogen was also able to inhibit the apoptotic process induced by either hydrogen peroxide (17) or doxorubicin (18). One of the significant genes which contains ERE on the gene $5^{\prime}$ region (19), a site that could affect cell apoptosis is a the $p S 2$ gene, also known as trefoil factor family-1 (TFF1) $(20,21)$.

TFF1 is a secreted protein that was first found in the MCF-7 breast cancer cell line (22). It is the first member of a trefoil factor family which includes TFF2 and TFF3 in mammals (23). Normally, TFF1 co-expresses with MUC5AC mucin and forms a stable cross-linked polymer for epithelial protection in various tissues, mainly in gastric mucosa, and is also expressed in tracheal mucosa and conjunctival goblet cells $(24,25)$. TFF1 can also stimulate epithelial cell migration that promotes a healing process but it is considered to promote metastasis in carcinoma $(23,26)$. An in vitro study showed that TFF1 can promote invasion of human cholangiocarcinoma cell lines and breast cancer cell lines $(26,27)$. By contrast, TFF1 was reported as a tumor suppressor protein in gastric cancer (28). TFF1 is upregulated in various pathological conditions including inflammation and cancer such as breast, ovarian, lung, prostate, pancreas, colon and cholangiocarcinoma $(23,26)$. A previous study reported high expression of TFF1 detected in $74 \%$ of breast cancer tissues, with correlation to the hormonal receptor status (29), while normal breast tissue showed minimal expression of TFF1 $(25,30)$. TFF1 was also detected in breast cancer patient sera which correlated with the tumor proliferative rate (31). In laboratory experiments a controversy has developed over whether TFF1 enhances (32) or suppresses (33) oncogenicity of breast cancer. The discussion revolves around the possible differences in cell lines and methods that might produce the different outcomes. TFF1, however, could be used as marker for responding to hormonal therapy such as aromatase inhibitors and ER antagonist tamoxifen in clinical therapy $(34,35)$.

Previous in vitro experiments showed that TFF1 could suppress apoptosis stimulated by chemically-induced Bad expression or anchorage-dependent apoptosis in gastrointestinal rat IEC18 diploid intestinal cells, human HCT116 colon cancer cells and AGS gastric cancer cells (20). In addition, TFF1 could protect Chang conjunctival cells from chemical or ultraviolet radiation-induced apoptosis (21). TFF1 is also a downstream product of estrogenic stimulant and estrogen itself could inhibit induced-apoptosis in breast cancer cells; TFF1 also showed high expression in breast cancer tissue, particularly in ER positive tissues, which naturally resist cyto- toxic chemotherapeutic agents. The hypothesis that estrogen could inhibit chemical-induced apoptosis in breast cancer cells via a TFF1-dependent mechanism merits further investigation. In the present study, it was demonstrated that TFF1 stable knockdown of MCF-7 cells as a tool for studying doxorubicininduced apoptosis in the presence of $17 \beta$-estradiol (E2) could show apoptosis protection or not. The phenomenon was also confirmed by reversing the experiments using anti-TFF1 antibody and recombinant TFF1 (rTFF1) for treating the mock control and knockdown conditions. The apoptotic process was analyzed using flow cytometry, viable cell counting and an apoptosis protein array and the proteins of interest were then chosen for final functional assay. The present study further clarifies the role of TFF1 in estrogen-induced breast cancer resistance to chemotherapy.

\section{Materials and methods}

Cell line and chemical agents. ER positive human breast adenocarcinoma MCF-7 cells were grown as a monolayer in Dulbecco's modified Eagle's medium (DMEM) (Gibco, Invitrogen, Carlsbad, CA, USA) supplemented with $10 \%$ fetal bovine serum (FBS), antibiotics and an antimycotic including $0.1 \mathrm{U} / \mathrm{ml}$ penicillin $\mathrm{G}$ sodium, $0.1 \mathrm{mg} / \mathrm{ml}$ streptomycin and $5 \mathrm{mg} / \mathrm{ml}$ of amphotericin B. Cells were cultured in adhesive sterile culture flasks at $37^{\circ} \mathrm{C}$ in a $5 \% \mathrm{CO}_{2}$ humidified incubator. During the experiment, cells were passaged to appropriate containers allowing for adherence for $24 \mathrm{~h}$. Then the media was replaced by phenol red-free DMEM (Gibco-Invitrogen) supplemented with $10 \%$ charcoal stripped FBS (GibcoInvitrogen) to diminish the estrogenic effect of phenol red. In the conditions with estrogen treatment, media was added with $1 \mathrm{nM}$ E2 (Sigma-Aldrich, St. Louis, MO, USA). This pretreatment process was performed for $48 \mathrm{~h}$ and the media was changed to phenol red-free media to proceed with treatment conditions. Cells were treated with $1 \mathrm{nM} \mathrm{E2}, 1 \mu \mathrm{M}$ doxorubicin (Pfizer, Midtown Manhattan, NY, USA), $10 \mu \mathrm{M}$ fulvestrant (Sigma-Aldrich), $100 \mu \mathrm{g} / \mathrm{ml}$ anti-TFF1 antibody (SigmaAldrich) or $10 \mu \mathrm{g} / \mathrm{ml}$ rTFF1 protein (Abcam, Cambridge, MA, USA), alone or in combinations.

TFF1 stable knockdown. MCF-7 breast cancer cells were transfected with MISSION ${ }^{\circledR}$ shRNA TFF1 pLKO.1-puro plasmid DNA vectors (Sigma-Aldrich) and selected by puromycin. Empty pLKO.1-puro plasmid (Sigma-Aldrich) was used as mock control. The transfection process was performed using Lipofectamine ${ }^{\circledR} 2000$ (Invitrogen) following the manufacturer's protocol. Stable transfected cells were selected using an appropriate dose of puromycin (Sigma-Aldrich) and gradually increased up to $10 \mathrm{mg} / \mathrm{ml}$ with a 7-day duration. The knockdown of TFF1 was analyzed by immunoblotting analysis. Cells with least expression of TFF1 were used as TFF1-knockdown (TFF1-KD) cells.

Immunoblotting analysis. Proteins from the whole cell lysate were separated by 15-20\% SDS-polyacrylamide gel electrophoresis. Subsequently, proteins for western blots were transferred to PVDF membranes for immunodetection. For TFF1, the membranes were probed with polyclonal anti-human TFF1 (Sigma-Aldrich; 1:2,000). Then, detection of antibody binding 
was performed using horseradish peroxide-labeled goat antirabbit secondary antibody (Abcam; 1:2,000). The signal was developed using SuperSignal West Pico ${ }^{\circledR}$ Chemiluminescent Substrate (Thermo Fisher Scientific, Rockford, IL, USA) and detected with autoradiography. $\beta$-actin was used as a loading control with the same procedure.

Apoptosis measurement. An apoptosis assay of mock and TFF1-KD MCF-7 cells treated with doxorubicin or E2 alone or in combination was performed using flow cytometry after fluorescein isothiocyanate (FITC)-conjugated Annexin V/propidium iodide (PI) staining by BD Pharmingen ${ }^{\mathrm{TM}}$ FITC Annexin V Apoptosis Detection kit I (Becton-Dickinson, Franklin Lakes, NJ, USA). Cells were seeded in a 6-well plate. After the pretreatment process, the media was changed to similar media and doxorubicin was added in the doxorubicin-treated conditions. At $18 \mathrm{~h}$ after treatment, both detached and adherent cells were harvested. The cells were centrifuged to remove the media followed by an ice cold phosphate-buffer saline (PBS) wash. The cells were gently resuspended in Annexin $\mathrm{V}$ binding buffer (provided by manufacturer) and $\sim 1 \times 10^{5}$ cells were transferred to a 5-ml tube, with FITC-Annexin V and PI added and incubated in the dark at $20-25^{\circ} \mathrm{C}$ for $15 \mathrm{~min}$ and fixed by freshly prepared $4 \%$ paraformaldehyde for $15 \mathrm{~min}$. All processes were performed on ice. The fluorescence intensity was determined by BD FACsFlow ${ }^{\mathrm{TM}}$ FACS analysis (Becton-Dickinson).

Assessment of cell death determined after neutralizing with anti-TFF1 antibody or antagonizing estrogen with fulvestrant or reconstitution of TFF1 to the TFF1-KD cells. Mock or TFF1-KD MCF-7 cells were seeded in a 96-well plate and pre-treated with phenol red-free media with or without E2 as explained. The respective wells were then treated with doxorubicin, E2, anti-human TFF1 antibody, full length rTFF1 or fulvestrant alone or in combination prepared in $200 \mu 1$ of media. Untreated cells were used as background controls. Eighteen hours after treatment, total cells were harvested then stained by trypan blue for viable cell counting under the microscope. The experiments were performed multiple times independently with duplication each time.

Protein array. Mock or TFFI-KD MCF-7 cells were seeded in $75-\mathrm{cm}^{2}$ cell culture flasks. After the pre-treatment process, the medium was replaced with medium containing doxorubicin alone or in combination with E2. Eighteen hours after treatment, the cells were harvested for analysis of apoptosis protein expression. The apoptosis protein assay used in the present study was Proteome Profiler ${ }^{\mathrm{TM}}$ Human Apoptosis array (R\&D Systems, Minneapolis, MN, USA). According to the manufacturer's instructions, the remaining PBS was removed and $\sim 1 \times 10^{7}$ cells were solubilized in lysis buffer provided by the manufacturer. A total protein assay was performed on the supernatant using Coomassie Plus ${ }^{\mathrm{TM}}$ (Bradford) protein assay (Thermo Fisher Scientific). Appropriate dilutions of protein in the lysates were prepared as per the maximum allowable volume per array recommended by the manufacturer. The recommended quantity of lysates was diluted and pipetted onto the membranes and incubated overnight at $2-8^{\circ} \mathrm{C}$ on a rocking platform shaker. Biotinylated secondary antibody cocktail provided by the manufacturer was pipetted onto membranes and incubated for $1 \mathrm{~h}$. After the washing process, the membranes were incubated with streptavidin-HRP provided by the manufacturer for $30 \mathrm{~min}$. The signals were developed using chemiluminescent reagents and then exposed to X-ray films. The positive signals were analyzed using ImageJ software (National Institutes of Health, Bethesda, MD, USA).

Determination of catalase activity. Dichromate in the presence of acetic acid and hydrogen peroxide $\left(\mathrm{H}_{2} \mathrm{O}_{2}\right)$ with heat was reduced to chromic acetate that can be measured colorimetrically and when compared to $\mathrm{H}_{2} \mathrm{O}_{2}$ concentration. The catalase enzyme eliminated $\mathrm{H}_{2} \mathrm{O}_{2}$ and the reaction was stopped by adding the dichromate/acetic acid mixture. Then the remaining $\mathrm{H}_{2} \mathrm{O}_{2}$ was determined by spectrophotometry at 570-610 nm. A catalase activity assay was modified from a previous report (36). Briefly, cells were seeded into the $25-\mathrm{cm}^{2}$ culture flask and pre-treated with phenol red-free media with or without E2 as explained. The cells were then treated with doxorubicin with or without E2 with non-treated controls. After $18 \mathrm{~h}$, the cells were harvested and $3 \times 10^{5}$ cells were washed with PBS and lysed in $100 \mu \mathrm{l}$ of chilled $0.1 \%$ Triton $\mathrm{X}-100$ in $10 \mathrm{mM}$ phosphate buffer at $\mathrm{pH}$ 7.4. An aliquot was taken for the Bradford assay and $90 \mu \mathrm{l}$ of cell lysates were added with bovine serum albumin and $\mathrm{H}_{2} \mathrm{O}_{2}$ to a final concentration of $0.5 \%(\mathrm{w} / \mathrm{v})$ and $20 \mathrm{mM}$. The reaction mixtures were incubated at $37^{\circ} \mathrm{C}$ for $10 \mathrm{~min}$ and the reactions were stopped by adding $30 \mu \mathrm{l}$ of freshly prepared $1.25 \%$ (w/v) $\mathrm{K}_{2} \mathrm{Cr}_{2} \mathrm{O}_{7}$ in $75 \%(\mathrm{v} / \mathrm{v})$ acetic acid and boiled for $10 \mathrm{~min}$. The reaction mixtures were then cooled on ice for $1 \mathrm{~min}$ and centrifuged at $12,000 \mathrm{rpm}, 4^{\circ} \mathrm{C}$ for $5 \mathrm{~min}$. Supernatants were obtained for measuring optical density at $570 \mathrm{~nm}$ by spectrophotometry. Specific activity of catalase (U/mg protein) was calculated and compared between conditions.

Statistical analysis. The comparison of the anti-apoptotic effect of TFF1 between the mock MCF-7 cell and the TFF1-KD MCF-7 cells under different treatment conditions were computed by the independent t-test using SigmaStat software version 3.5.1.2 (Systat Software, Richmond, CA, USA). A P-value of $<0.05$ was considered to indicate a statistically significant difference. For the protein array experiment, individual signals from gene expression with background subtracted were normalized with the average signal from of positive controls. Upregulation of protein was considered when the signal was increased more than 1.5 -fold and downregulation was the reduction $<0.66$-fold.

\section{Results}

Generation of TFF1-KD MCF7 breast cancer cells. Stable TFF1-KD MCF-7 cells were created by knocking down TFF1 using shRNA strategy. Five potential complementary sequence inserts for TFF1 gene were used to stably modify MCF-7 cells and an empty vector was used to generate the mock controls for the experiment. The transfected cells were then selected by gradually increasing up to $10 \mu \mathrm{g} / \mathrm{ml}$ of puromycin in complete media. The positively transfected cells, resistant to puromycin, were collected and propagated until adequate confluency was achieved. There were 5 sets of plasmids provided and labeled as Nos.1-5 as referred to in the RNAi Consortium (TRC) 
A

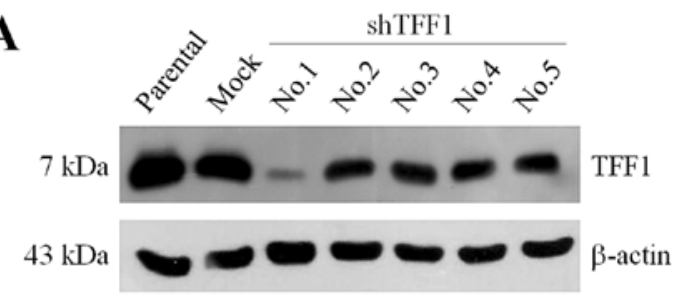

B

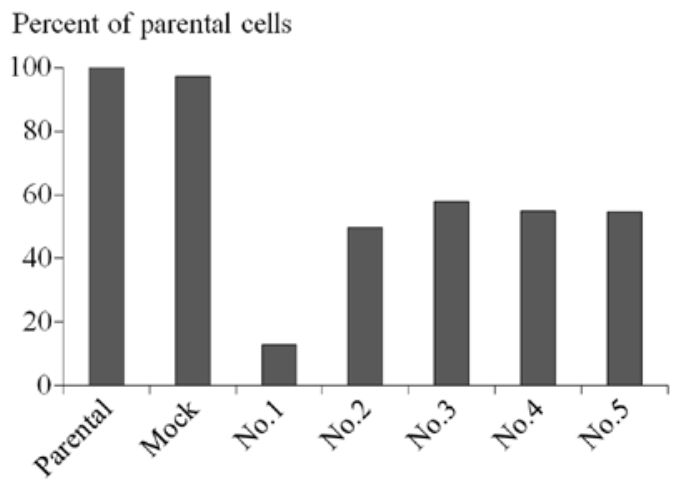

Figure 1. The expression of TFF1 trefoil protein in transfected MCF-7 cells. (A) Immunoblotting of lysates from MCF-7 cells transfected with plasmid vectors (Nos.1-5) carried out on a $15-20 \%$ gradient gel and probed by a specific antibody to TFF1. The ECL developed X-ray film represented the highest knockdown of TFF1 by No.1. (B) Analysis of TFF1 band intensity with $\beta$-actin as the loading control using ImageJ software.

numbers TRCN_00000033614 to TRCN_00000033618. The immunoblotting experiment showed that only No.1 could generate successful gene knockdown (Fig. 1A). No.1 showed the knockdown efficiency of $\sim 87 \%$ which had been achieved in comparison to the parental MCF-7 cells while the others showed $<50 \%$ and mock MCF-7 cells retained their intrinsic expression (Fig. 1B). No.1 was chosen as TFF1-KD cells used in further experiments.

Apoptosis assay. The mock and TFF1-KD cells were incubated with $1 \mu \mathrm{M}$ doxorubicin and $1 \mathrm{nM} \mathrm{E} 2$ in combination or separately for $18 \mathrm{~h}$ and were subjected to FITC-Annexin V and PI staining and analyzed by flow cytometry as shown by the dot plots in Fig. 2A. Treatment with $1 \mu \mathrm{M}$ doxorubicin showed a significant decrease in viability of both mock and TFF1-KD cells with or without $1 \mathrm{nM} \mathrm{E2}$ (Fig. 2B). In mock cells without E2 treatment, the percentage of viable cells was reduced $21.29 \%$ $(\mathrm{P}=0.004)$ but in the presence of $\mathrm{E} 2$ the reduction was minimized to only $8.84 \%(\mathrm{P}=0.032)$ (Fig. 2B) with a statistical significance of $\mathrm{P}=0.016$ (Fig. 2B). In TFF 1 -KD cells the percentage reductions of viable cells were not significantly different $(\mathrm{P}=0.335)$ (Fig. 2B) as $20.28 \%(\mathrm{P}=0.003)$ and $23.62 \%(\mathrm{P}=0.009)$ for the conditions of absence and presence of E2 (Fig. 2B).

Only mock cells with E2-treatment showed reduction of percentage in all dead cell components; early apoptosis $(2.23 \%$, $\mathrm{P}=0.308)$, late apoptosis $(3.31 \%, \mathrm{P}=0.005)$ and necrosis $(8.71 \%$, $\mathrm{P}=0.026)$ after 18 -h exposure to doxorubicin when compared to cells without E2 treatment (Fig. 2C). By contrast, E2 treatment did not show the significant difference of dead cell percentages in TFF1-KD cells after treatment with doxorubicin.
A

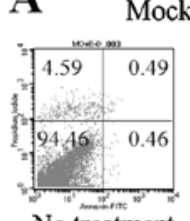

Mock cells

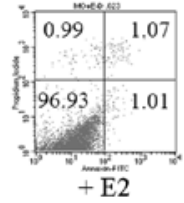

No treatment
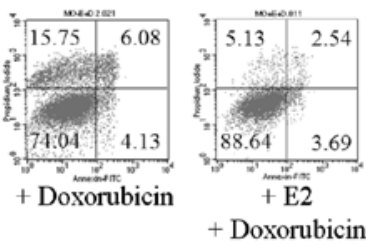

+ Doxorubicin

Doxorubicin
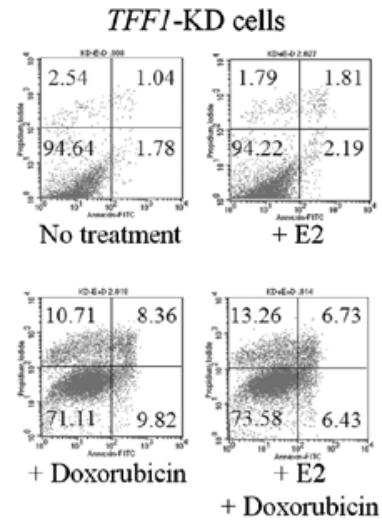

B Percent

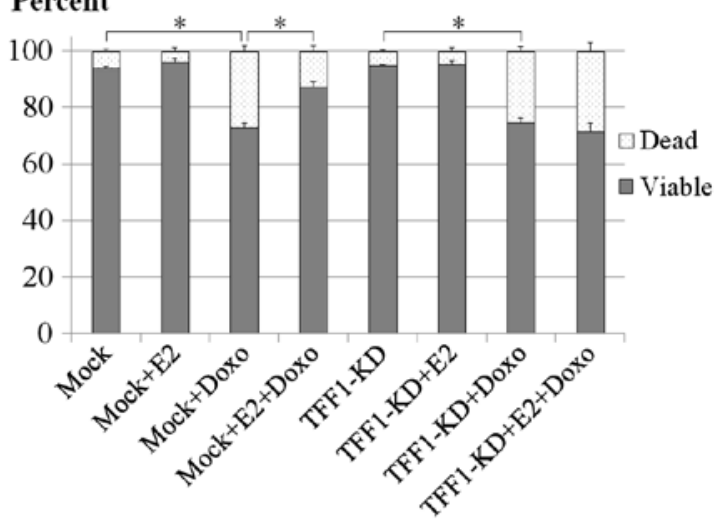

C

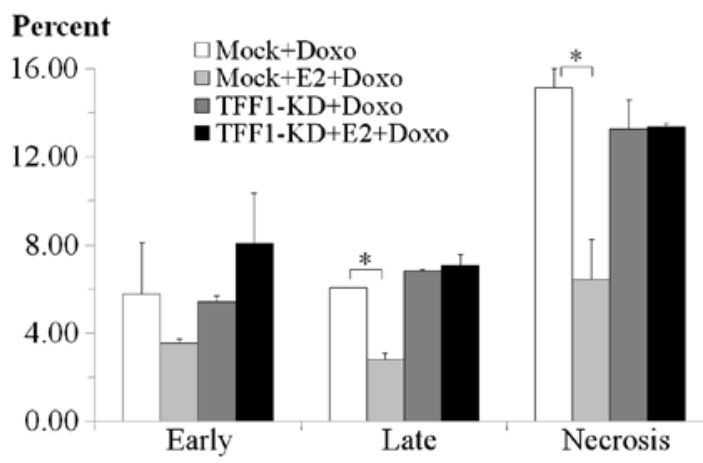

Figure 2. Apoptosis assay. (A) Representative dot plot diagram showing distribution of cells in various stages of apoptosis by staining with FITCAnnexin V and PI following treatment with or without doxorubicin and E2. Left-upper quadrant determination of necrotic cells, right-upper quadrant determination of late-apoptosis cells, left-lower quadrant determination of viable cells and right-lower quadrant determination of early-apoptosis cells. (B) Percentage viability of mock and TFF1-KD cells following treatment with or without doxorubicin and E2. Single E2 treatment had no significant effect on cell viability. Doxorubicin significantly reduced viability of both cells but E2 recovered only in mock cells. (C) Percentage of mock and TFF1-KD cells in stages of apoptosis following treatment with or without doxorubicin and E2. Co-treatment with E2 and doxorubicin showed significant reduction of late apoptosis and necrotic cells in mock cells but not in TFF1-KD cells. "Statistical significance at $\mathrm{P}<0.05$. E2, $1 \mathrm{nM} 17 \beta$-estradiol; Doxo, $1 \mu \mathrm{M}$ doxorubicin

The percentages were increased in early apoptosis $(2.64 \%$, $\mathrm{P}=0.249)$, late apoptosis $(0.27 \%, \mathrm{P}=0.53)$ and necrosis $(0.10 \%$, $\mathrm{P}=0.925$ ) (Fig. 2C) in E2-treated TFF1-KD cells. Collectively, doxorubicin treatment caused significant apoptosis in both the mock and TFF1-KD cells but the addition of E2 protected only the mock cells. 

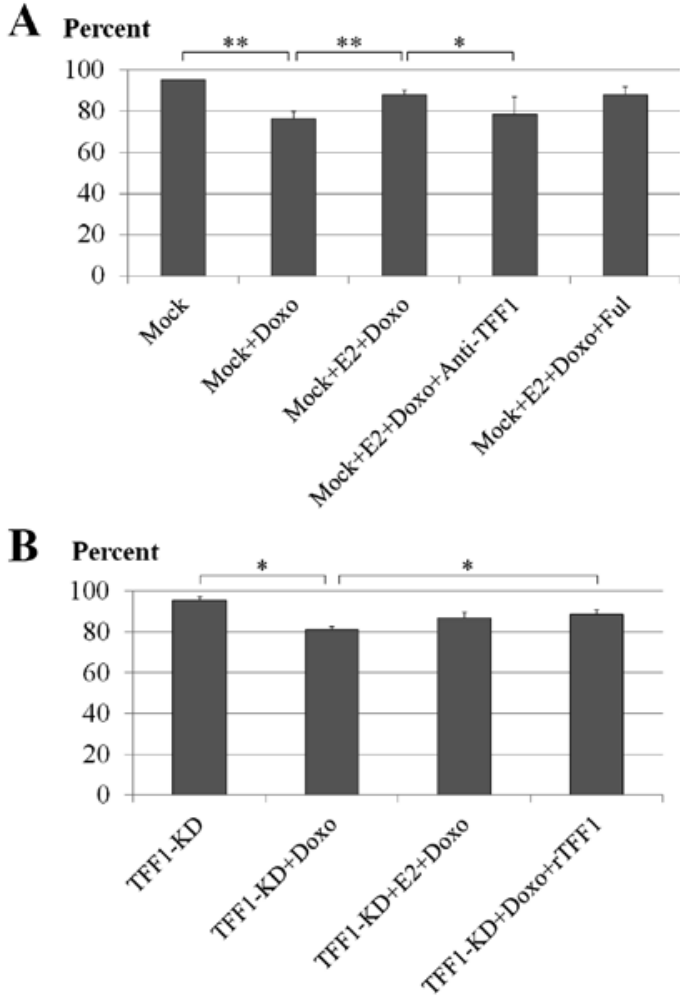

Figure 3. Viability of mock and TFF1-KD cells treated with doxorubicin, E2 and modifiers. (A) The effect of neutralizing secreted TFF1 by antiTFF1 antibody or antagonizing ERs by fulvestrant on mock cells co-treated with E2 and doxorubicin. Doxorubicin showed toxicity to cell viability and E2 significantly reversed this effect. Only anti-TFF1 antibody and not fulvestrant significantly inhibited the effect to E2. (B) The effect of rTFF1 and E2 to rescue the TFF1-KD cells from doxorubicin-induced apoptosis Doxorubicin showed toxicity to TFF1-KD cell viability and rTFF1 but E2 could not reverse this effect significantly. ${ }^{*}$ Statistical significance at $\mathrm{P}<0.05$. ${ }^{* *}$ Statistical significance at $\mathrm{P}<0.001$. E2, $1 \mathrm{nM} 17 \beta$-estradiol; Doxo, $1 \mu \mathrm{M}$ doxorubicin; Anti-TFF1, $100 \mu \mathrm{g} / \mathrm{ml}$ anti-TFF1 antibody; Ful, $10 \mu \mathrm{M}$ fulvestrant; rTFF1, $10 \mu \mathrm{g} / \mathrm{ml}$ recombinant TFF1.

Effect of neutralization of the secreted TFF1 with anti-TFF1 antibody. To evaluate if the neutralization of the secreted TFF1 had any effect on the doxorubicin-induced cell death, anti-TFF1 antibody was applied to mock MCF-7 cells treated with E2 and doxorubicin. Anti-TFF1 antibody used in this experiment was the same one that was used as primary antibody to detect TFF1 trefoil protein expression in the immunoblotting experiment and with this experimental concentration $(100 \mu \mathrm{g} / \mathrm{ml})$ it showed a minimal effect on cell viability after $18 \mathrm{~h}$ (data not shown). Doxorubicin caused significant cell death in the mock cells (76\% viable cells; $\mathrm{P}<0.001)$ compared to untreated cells $(95 \%$ viable cells) while E2 significantly rescued the cells ( $88 \%$ viable cells; $\mathrm{P}<0.001)$. The addition of anti-TFF1 antibody showed obvious neutralization of TFF1 by increasing the number of cell deaths significantly ( $79 \%$ viable cells; $\mathrm{P}=0.029)$ compared to the reverse effect exhibited by the E2 treatment (Fig. 3A).

Effect of ER antagonist fulvestrant. Estrogen has been shown to have pro-survival effects on the MCF-7 cells. In this experiment, the fulvestrant was expected to block the action of the added estrogen by downregulating the effective ERs in the MCF-7 cells, to further elucidate the pro-survival role of estrogen-induced TFF1 following chemotherapeutic drug

\begin{tabular}{|c|c|c|c|c|}
\hline M & MD & MDE & $\mathrm{KDE}$ & Position map \\
\hline $8:: 8$ & 8 & $8: 8$ & $8: 8$ & 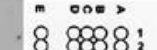 \\
\hline$:::$ & & & & 880 \\
\hline$:$ & : & 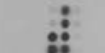 & $:$ & \& \\
\hline 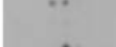 & & :. & 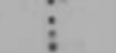 & $808:$ \\
\hline :. & & $\because$ & $a$ & 8 \\
\hline 8 & & :: & $:$ & 838 \\
\hline 8 & $::$ & :: & : & 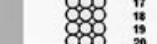 \\
\hline$:: 8$ & ${ }^{: 28}$ & :: & $::$ & 88 \\
\hline
\end{tabular}

Figure 4. Apoptosis protein array for the mock and TFF1-KD MCF-7 cells treated with doxorubicin and in the presence or absence of E2 for $18 \mathrm{~h}$. The ECL developed apoptosis protein array film with company position map. Position A1, A2, A23, A24, E1 and E2 were positive controls and position D23 and D24 were negative controls (background). M, untreated mock cells; MD, mock cells treated with $1 \mu \mathrm{M}$ doxorubicin; MDE, mock cells treated with $1 \mathrm{nM} 17 \beta$-estradiol and $1 \mu \mathrm{M}$ doxorubicin; KDE, TFF1-KD cells treated with $1 \mathrm{nM} 17 \beta$-estradiol and $1 \mu \mathrm{M}$ doxorubicin.

treatment. The result showed, however, that the fulvestrant failed to diminish the pro-survival effect of E2 on doxorubicin-treated mock MCF-7 cells (88\% viable cells; $\mathrm{P}=0.953$ ) compared to E2 and doxorubicin-treated mock cells $(88 \%$ viable cells) (Fig. 3A).

Treatment of the TFF1-KD cells with rTFF1 and E2. TFF1 trefoil protein was reconstituted in the TFF1-KD MCF-7 cells by treating with rTFF1 during incubation with E2 and doxorubicin. The ability of the rTFF1 to rescue the TFF1-KD MCF-7 cells was examined in cells treated with E2 and doxorubicin. By comparing to untreated cells $(95 \%$ viable cells), doxorubicin treatment showed induction of cell death in the TFF1-KD cells ( $81 \%$ viable cells; $\mathrm{P}=0.013)$ and $\mathrm{E} 2 \mathrm{did}$ not significantly recover this effect in these cells $(87 \%$ viable cells; $\mathrm{P}=0.124)$. The pro-survival effect by rTFF1 was evident at $100 \mu \mathrm{g} / \mathrm{ml}$ with statistical significance $(89 \%$ viable cells; $\mathrm{P}=0.037$ ) (Fig. 3B).

Apoptosis protein array. To investigate changes in the apoptosis protein expression under different conditions, four different treatment conditions were set up including nontreated controls. Doxorubicin-mediated protein expressions were compared to those of the untreated mock MCF-7 cells. The doxorubicin and E2 co-treated condition was compared to the doxorubicin-treated mock cells to examine the E2 effect. The TFF1 effect was compared between the mock and TFF1-KD cells co-treated with doxorubicin and E2. Fig. 4 represents the ECL developed protein array results with the aforementioned conditions.

Of the 35 proteins on the array, doxorubicin-treated mock MCF-7 cells showed upregulated expression of 24 proteins, 12 pro-apoptosis proteins and 12 anti-apoptosis proteins, compared to non-treated mock control cells while no significant reduction was observed between these conditions (Table I). When mock MCF-7 cells, which were co-treated with doxorubicin and E2, were compared to doxorubicintreated cells, 4 upregulated proteins (1 pro-apoptosis protein and 3 anti-apoptosis proteins) and 5 downregulated proteins (3 pro-apoptosis proteins 2 anti-apoptosis proteins) were 
Table I. Calculated signal from apoptosis protein arrays.

\begin{tabular}{|c|c|c|c|c|c|c|c|c|c|}
\hline \multirow[b]{2}{*}{ Position } & \multirow[b]{2}{*}{ Protein } & \multirow[b]{2}{*}{ Pro/Anti ${ }^{\mathrm{a}}$} & \multicolumn{4}{|c|}{ Calculated signal ${ }^{\mathrm{b}}$} & \multicolumn{3}{|c|}{ Ratio $^{c}$} \\
\hline & & & $\mathrm{M}$ & MD & MDE & KDE & $\mathrm{MD} / \mathrm{M}$ & MDE/MD & $\mathrm{KDE} / \mathrm{MDE}$ \\
\hline $\mathrm{B} 1,2$ & Bad & $\mathrm{P}$ & 0.144 & 0.230 & 0.113 & 0.056 & $1.6^{\mathrm{d}}$ & $0.5^{\mathrm{d}}$ & 0.5 \\
\hline $\mathrm{B} 3,4$ & Bax & $\mathrm{P}$ & 0.359 & 0.655 & 0.442 & 0.431 & $1.8^{\mathrm{d}}$ & $0.7^{\mathrm{d}}$ & 1.0 \\
\hline B5,6 & $\mathrm{Bcl}-2$ & A & 0.014 & 0.050 & 0.041 & 0.017 & $3.6^{\mathrm{d}}$ & 0.8 & $0.4^{\mathrm{e}}$ \\
\hline $\mathrm{B} 7,8$ & Bcl-x & A & 0.004 & 0.099 & 0.022 & 0.008 & $26.9^{d}$ & $0.2^{\mathrm{d}}$ & $0.4^{\mathrm{e}}$ \\
\hline B9,10 & Pro-caspase-3 & $\mathrm{P}$ & 0.001 & 0.013 & 0.016 & 0.003 & $15.6^{\mathrm{d}}$ & 1.2 & $0.2^{\mathrm{d}}$ \\
\hline B11,12 & Cleaved caspase-3 & $\mathrm{P}$ & 0.055 & 0.039 & 0.073 & 0.044 & 0.7 & $1.9^{\mathrm{d}}$ & 0.6 \\
\hline B13,14 & Catalase & A & 0.035 & 0.063 & 0.323 & 0.192 & $1.8^{\mathrm{d}}$ & 5.1 & 0.6 \\
\hline B15,16 & cIAP-1 & A & 0.021 & 0.092 & 0.107 & 0.023 & $4.5^{\mathrm{d}}$ & 1.2 & 0.2 \\
\hline B17,18 & cIAP-2 & A & 0.003 & 0.010 & 0.009 & 0.007 & $2.9^{\mathrm{d}}$ & 0.9 & 0.8 \\
\hline $\mathrm{B} 19,20$ & Claspin & A & 0.017 & 0.105 & 0.116 & 0.026 & $6.2^{\mathrm{e}}$ & 1.1 & $0.2^{\mathrm{d}}$ \\
\hline B21,22 & Clusterin & A & 0.010 & 0.021 & 0.036 & 0.008 & $2.0^{\mathrm{d}}$ & $1.7^{\mathrm{d}}$ & $0.2^{\mathrm{d}}$ \\
\hline B23,24 & Cytochrome $c$ & $\mathrm{P}$ & 0.532 & 0.638 & 0.643 & 0.531 & $1.2^{\mathrm{d}}$ & 1.0 & 0.8 \\
\hline $\mathrm{C} 1,2$ & TRAIL R1/DR4 & $\mathrm{P}$ & 0.121 & 0.646 & 0.565 & 0.176 & $5.4^{\mathrm{d}}$ & 0.9 & $0.3^{\mathrm{d}}$ \\
\hline $\mathrm{C} 3,4$ & TRAIL R2/DR5 & $\mathrm{P}$ & 0.030 & 0.849 & 0.520 & 0.296 & $28.0^{\mathrm{e}}$ & $0.6^{\mathrm{d}}$ & $0.6^{\mathrm{d}}$ \\
\hline $\mathrm{C} 5,6$ & FADD & $\mathrm{P}$ & 0.433 & 0.593 & 0.542 & 0.334 & $1.4^{\mathrm{d}}$ & 0.9 & $0.6^{\mathrm{e}}$ \\
\hline $\mathrm{C} 7,8$ & Fas/TNFRSF6 & $\mathrm{P}$ & 0.026 & 0.636 & 0.597 & 0.084 & $25.0^{\mathrm{e}}$ & 0.9 & $0.1^{\mathrm{d}}$ \\
\hline $\mathrm{C} 9,10$ & HIF-1a & $\mathrm{P}$ & 0.003 & 0.044 & 0.045 & 0.009 & $17.7^{\mathrm{d}}$ & 1.0 & $0.2^{\mathrm{d}}$ \\
\hline $\mathrm{C} 11,12$ & HO-1/HMOX/HSP32 & A & 0.210 & 0.282 & 0.381 & 0.032 & 1.3 & $1.4^{\mathrm{d}}$ & $0.1^{\mathrm{e}}$ \\
\hline $\mathrm{C} 13,14$ & HO-2/HMOX2 & A & 0.394 & 0.574 & 0.642 & 0.506 & $1.5^{\mathrm{d}}$ & 1.1 & $0.8^{\mathrm{d}}$ \\
\hline $\mathrm{C} 15,16$ & HSP27 & A & 0.468 & 0.866 & 0.620 & 0.557 & $1.9^{\mathrm{d}}$ & $0.7^{\mathrm{d}}$ & 0.9 \\
\hline $\mathrm{C} 17,18$ & HSP60 & A & 0.021 & 0.061 & 0.095 & 0.125 & $2.9^{\mathrm{d}}$ & $1.6^{\mathrm{d}}$ & 1.3 \\
\hline $\mathrm{C} 19,20$ & HSP70 & A & 0.602 & 0.436 & 0.604 & 0.582 & $0.7^{\mathrm{d}}$ & $1.4^{\mathrm{d}}$ & 1.0 \\
\hline $\mathrm{C} 21,22$ & HTRA2/Omi & $\mathrm{P}$ & 0.227 & 0.261 & 0.337 & 0.025 & 1.2 & $1.3^{\mathrm{d}}$ & $0.1^{\mathrm{d}}$ \\
\hline $\mathrm{C} 23,24$ & Livin & A & 0.006 & 0.006 & 0.008 & 0.007 & 1.0 & 1.4 & 0.8 \\
\hline $\mathrm{D} 1,2$ & PON2 & A & 0.008 & 0.041 & 0.011 & 0.010 & $4.8^{\mathrm{d}}$ & $0.3^{\mathrm{d}}$ & 0.9 \\
\hline $\mathrm{D} 3,4$ & p21/CIP1/CDNK1A & A & 0.051 & 0.952 & 0.696 & 0.186 & $18.7^{\mathrm{d}}$ & $0.7^{\mathrm{d}}$ & $0.3^{\mathrm{d}}$ \\
\hline D5,6 & p27/Kip1 & A & 0.015 & 0.061 & 0.047 & 0.008 & $4.2^{\mathrm{d}}$ & $0.8^{\mathrm{d}}$ & $0.2^{\mathrm{d}}$ \\
\hline $\mathrm{D} 7,8$ & Phospho-p53 (S15) & $\mathrm{P}$ & 0.022 & 0.631 & 0.753 & 0.410 & $28.2^{\mathrm{e}}$ & 1.2 & $0.5^{\mathrm{d}}$ \\
\hline D9,10 & Phospho-p53 (S46) & $\mathrm{P}$ & 0.002 & 0.711 & 0.636 & 0.305 & $356.4^{\mathrm{e}}$ & 0.9 & $0.5^{\mathrm{d}}$ \\
\hline $\mathrm{D} 11,12$ & Phospho-p53 (S392) & $\mathrm{P}$ & 0.007 & 0.896 & 0.794 & 0.464 & $127.4^{\mathrm{d}}$ & 0.9 & $0.6^{\mathrm{d}}$ \\
\hline D13,14 & Phospho-Rad17 (S635) & $\mathrm{P}$ & 0.012 & 0.076 & 0.047 & 0.019 & $6.4^{\mathrm{d}}$ & $0.6^{\mathrm{d}}$ & $0.4^{\mathrm{d}}$ \\
\hline D15,16 & SMAC/Diablo & $\mathrm{P}$ & 0.791 & 1.206 & 0.872 & 0.544 & $1.5^{\mathrm{d}}$ & $0.7^{\mathrm{d}}$ & $0.6^{\mathrm{d}}$ \\
\hline D17,18 & Survivin & A & 0.020 & 0.026 & 0.029 & 0.008 & 1.3 & 1.1 & $0.3^{\mathrm{d}}$ \\
\hline D19,20 & TNF RI/TNFRSF1A & $\mathrm{P}$ & 0.019 & 0.019 & 0.026 & 0.006 & 1.0 & $1.4^{\mathrm{d}}$ & $0.2^{\mathrm{d}}$ \\
\hline $\mathrm{D} 21,22$ & XIAP & A & 0.274 & 0.350 & 0.337 & 0.039 & $1.3^{\mathrm{d}}$ & 1.0 & $0.1^{\mathrm{e}}$ \\
\hline
\end{tabular}

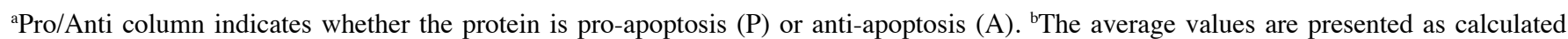
signal. ${ }^{\circ}$ The comparisons between conditions were performed and are presented as ratios. ${ }^{\mathrm{d}}$ Statistical significance at $\mathrm{P}<0.05$. ${ }^{\mathrm{e}} \mathrm{Statistical}$ significance at $\mathrm{P}<0.001$.

observed (Table I). The comparison between TFF1-KD cells and mock cells co-treated with doxorubicin and E2 demonstrated only downregulated expression on 26 proteins (15 pro-apoptosis proteins and 11 anti-apoptosis proteins) but not upregulated proteins (Table I). Among these three comparisons, proteins which could be regulated by E2 treatment and TFF1 expression and correlated with the apoptotic status of the cell were catalase and clusterin. Since catalase is the intracellular enzyme, it was chosen to analyze its activity.

Catalase assay. To correlate catalase expression in the protein array, the cells were treated under similar conditions and their specific catalase activity was determined. Doxorubicin-treated mock MCF-7 cells showed minimal increase of catalase- 


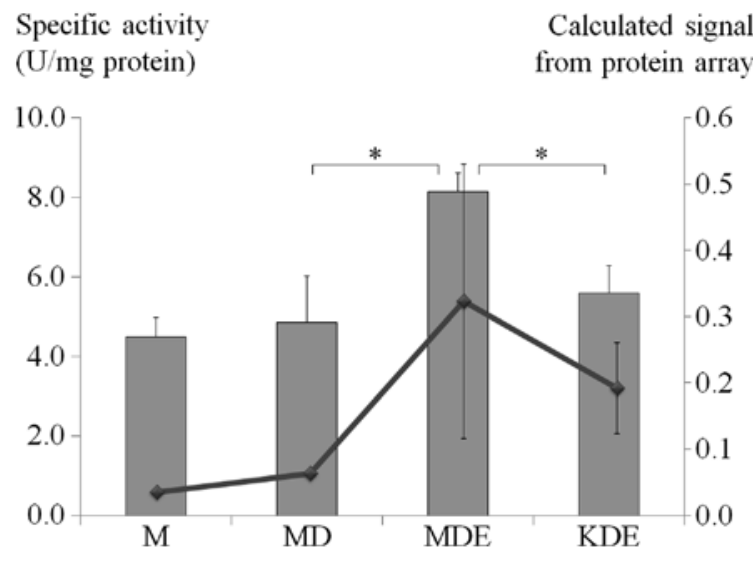

Figure 5. Catalase enzymatic assays. The specific activity of catalase was measured between cells in the same condition of protein array and shown as bar graphs with the scale on left vertical axis. Calculated signals of the same conditions from the protein array are shown as dot and line with scale on right vertical axis. E2 shows a significant increase of catalase activity in doxorubicin-treated mock cells but not TFF1-KD cells. "Statistical significance at $\mathrm{P}<0.05$. $\mathrm{M}$, untreated mock cells; $\mathrm{MD}$, mock cells treated with $1 \mu \mathrm{M}$ doxorubicin, MDE, mock cells treated with $1 \mathrm{nM} 17 \beta$-estradiol and $1 \mu \mathrm{M}$ doxorubicin; KDE, TFF1-KD cells treated with $1 \mathrm{nM} 17 \beta$-estradiol and $1 \mu \mathrm{M}$ doxorubicin.

specific activity compared to non-treated control cells. However, when mock MCF-7 cells which co-treated with doxorubicin and E2, were compared to doxorubicin-treated cells, a 1.7-fold increase of catalase specific activity $(\mathrm{P}=0.018)$ was observed and it showed a reduction to 0.69 -fold change in TFF1-KD MCF-7 cells co-treated with doxorubicin and E2 $(\mathrm{P}=0.006)($ Fig. 5).

\section{Discussion}

Breast cancer is one of the most common types of cancer worldwide (1). In advanced stages, chemotherapy is important for treatment (4). The use of cytotoxic drugs has been shown to be unsuccessful in ER positive patients (7-9). While almost all chemotherapeutic agents can induce apoptosis, estrogen is able to inhibit this action. It has been reported that estrogen inhibits doxorubicin-induced apoptosis in MFC-7 breast cancer cells (18). In addition, estrogen could stimulate expression of TFF1 trefoil protein, a small protein which has been reported for its function to protect various cell types in induced-apoptosis in vitro $(20,21)$. Thus, it is of note that estrogen could stimulate apoptosis resistance in breast cancer cells via a TFF1 dependent mechanism. This can be lead to the understanding of some mechanisms in the drug resistance of breast cancer.

In the present study, the role of TFF1 in estrogen-promoted resistance to doxorubicin in ER positive MCF-7 breast cancer cells was introduced. Stable knockdown of TFF1 gene in MCF-7 cells was generated (Fig. 1) and used to test the sensitivity to doxorubicin treatment compared to empty plasmid transfected mock control cells in the presence or absence of E2. The apoptosis cells were measured by fluorescence staining by flow cytometry. The results showed that with the stimulation of apoptosis by doxorubicin, E2 suppressed this process in mock cells but not in TFF1-KD cells (Fig. 2). This confirmed that E2 could diminish the cytotoxic effect of doxorubicin by reduced apoptosis. In addition, with TFF1 gene knockdown, the anti-apoptosis effect of E2 was decreased. It may be that TFF1 is involved in this mechanism. In addition, the experiment of mock cells treated with anti-TFF1 antibody showed that E2 could not inhibit doxorubicin-induced cell death similar to TFF1-KD cells (Fig. 3A). Moreover, the experiment of TFF1-KD cells treated with rTFF1 demonstrated resistance to doxorubicin cytotoxicity as shown in mock cells treated with E2 (Fig. 3B). These results confirmed the anti-apoptotic function of TFF1 trefoil protein.

The apoptosis protein array experiment indicated that mock MCF-7 cells treated with doxorubicin showed upregulation of expression of almost all apoptosis-related proteins, including both pro- and anti-apoptosis proteins, but no significantly downregulated proteins (Fig. 4). These results showed either a similarity or difference to previous studies of doxorubicin treated MCF-7 cells by an oligonucleotide microarray (37-39). The differences in either cell treatment protocols or gene expression detecting methods might lead to different interpretation, which should be confirmed in protein expression levels and functional analysis. In the estrogen treatment condition, the results demonstrated that E2 could help mock cells from doxorubicin-induced cell death and showed that some apoptosis proteins changed as compared to mock cells treated with only doxorubicin (Fig. 4 and Table I). Catalase, clusterin and Hsp60, which are anti-apoptosis proteins, were upregulated while Bad, Trail R2 and phospho-Rad17 (S635), which are pro-apoptosis proteins, were downregulated. This may suggest that changes of these proteins were necessary for E2 protection of cell apoptosis induced by doxorubicin. By contrast, pro-apoptosis protein cleaved caspase-3 was detected at a higher level in E2 and doxorubicin-treated mock cells than in only doxorubicin-treated mock cells but pro-caspase-3 protein was not significantly altered. In addition, anti-apoptosis proteins Bcl-x and Pon2 were downregulated. These results did not correspond to cell death, so it could not be concluded that gene expression of either caspase-3, Bcl-x or Pon 2 had a role in this situation.

The comparison between TFF1-KD cells and mock cells co-treated with E2 and doxorubicin showed downregulated expression of 15 pro-apoptosis proteins and 11 anti-apoptosis proteins (Table I). Among these protein expressions and modifications, only catalase and clusterin showed to correspond to cell death, which might be regulated by E2 and TFF1. Functional analyses of catalase in the similar conditions with apoptosis protein array studies were performed and the results confirmed the expression of catalase proteins (Fig. 5). By contrast, previous studies showed that estrogen could inhibit catalase expression in MCF-7 cells $(40,41)$. This could be explained by the fact that the conditions used in previous studies did not stimulate apoptosis by a cytotoxic agent, so catalase expression might be the compensation for inducedapoptosis stimulated by E2 and TFF1. To the best of our knowledge, no previous report demonstrates the relationship between catalase expression and TFF1. Clusterin is an intracellular protein which showed protective activity to apoptosis and was expressed in various types of cancer (42). Clusterin expression could be induced by estrogen and may lead to resistance to the chemotherapeutic agent paclitaxel (43). Thus, 
clusterin is another attractive protein for further study into the mechanism of estrogen and TFF1-related drug resistance in breast cancer.

Fulvestrant, formerly known as ICI 182,780 , is an antiestrogenic agent which is used in clinical practice (44). It has been shown that fulvestrant enhances doxorubicin cytotoxicity in MCF-7 cells in both in vitro and in vivo studies $(44,45)$. Therefore, in the present study fulvestrant was expected to show an antagonistic effect to estrogen in E2-doxorubicin co-treated MCF-7 cells; however, the results showed that fulvestrant could not express this effect. This may be explained by the fact that in the presence of estrogen and with a short time of 18-h exposure to fulvestrant this effect might not be as clear as with 72 -h treatment or more as in previous reports $(44,45)$. Thus, fulvestrant may be considered for study in clinical trials in combination with chemotherapeutic agents using another system (44).

In conclusion, estrogen showed protection of MCF-7 cells from doxorubicin-induced apoptosis but not in TFF1-KD cells. This indicated a possible TFF1 role in estrogen-induced apoptosis resistance. In this experiment, fulvestrant was not able to inhibit estrogen-induced apoptosis resistance. Catalase was shown as an effective mediator in TFF1-mediated estrogeninduced apoptosis resistance. Therefore, the TFF1 gene may be a target for enhancing sensitivity to chemotherapy in breast cancer treatment.

\section{Acknowledgements}

The present study was supported by the Faculty of Medicine, Siriraj Hospital, Mahidol University. The authors thank Professor Pornchai O-chareonrat (Department of Surgery, Faculty of Medicine Siriraj Hospital, Mahidol University) for providing the MCF-7 breast cancer cell line. The authors would also like to thank Professor James A. Will (University of Wisconsin-Madison) for editorial comments on the manuscript.

\section{References}

1. Ferlay J, Shin HR, Bray F, Forman D, Mathers C and Parkin DM: Estimates of worldwide burden of cancer in 2008: GLOBOCAN 2008. Int J Cancer 127: 2893-2917, 2010.

2. Porter P: 'Westernizing' women's risks? Breast cancer in lowerincome countries. N Engl J Med 358: 213-216, 2008.

3. Tuttle TM, Rueth NM, Abbott A and Virnig BA: United States trends in the surgical treatment of primary breast cancer. World J Surg 36: 1475-1479, 2012.

4. Arslan C, Altundag K and Dizdar O: Emerging drugs in metastatic breast cancer: an update. Expert Opin Emerg Drugs 16: 647-667, 2011.

5. Stopeck AT, Brown-Glaberman U, Wong HY, Park BH, Barnato SE, Gradishar WJ, Hudis CA and Rugo HS: The role of targeted therapy and biomarkers in breast cancer treatment. Clin Exp Metastasis 29: 807-819, 2012.

6. Jordan VC and O'Malley BW: Selective estrogen-receptor modulators and antihormonal resistance in breast cancer. J Clin Oncol 25: 5815-5824, 2007.

7. Allegra JC, Lippman ME, Thompson EB and Simon R: An association between steroid hormone receptors and response to cytotoxic chemotherapy in patients with metastatic breast cancer Cancer Res 38: 4299-4304, 1978.

8. Kuerer HM, Newman LA, Smith TL, Ames FC, Hunt KK, Dhingra K, Theriault RL, Singh G, Binkley SM, Sneige N, Buchholz TA, Ross MI, McNeese MD, Buzdar AU, Hortobagyi GN and Singletary SE: Clinical course of breast cancer patients with complete pathologic primary tumor and axillary lymph node response to doxorubicin-based neoadjuvant chemotherapy. J Clin Oncol 17: 460-469, 1999.
9. Conforti R, Boulet T, Tomasic G, Taranchon E, Arriagada R, Spielmann M, Ducourtieux M, Soria JC, Tursz T, Delaloge S, Michiels S and Andre F: Breast cancer molecular subclassification and estrogen receptor expression to predict efficacy of adjuvant anthracyclines-based chemotherapy: a biomarker study from two randomized trials. Ann Oncol 18: 1477-1483, 2007.

10. Pritchard JE, Dillon PM, Conaway MR, Silva CM and Parsons SJ: A mechanistic study of the effect of doxorubicin/adriamycin on the estrogen response in a breast cancer model. Oncology 83: 305-320, 2012.

11. Dickson RB and Stancel GM: Estrogen receptor-mediated processes in normal and cancer cells. J Natl Cancer Inst Monogr 2000: 135-145, 2000.

12. Lewis-Wambi JS and Jordan VC: Estrogen regulation of apoptosis: how can one hormone stimulate and inhibit? Breast Cancer Res 11: 206, 2009.

13. Haddow A, Watkinson JM, Paterson E and Koller PC: Influence of synthetic oestrogens on advanced malignant disease. Br Med J 2: 393-398, 1944.

14. Ward HW: Anti-oestrogen therapy for breast cancer: a trial of tamoxifen at two dose levels. Br Med J 1: 13-14, 1973.

15. Lewis JS, Meeke K, Osipo C, Ross EA, Kidawi N, Li T, Bell E, Chandel NS and Jordan VC: Intrinsic mechanism of estradiolinduced apoptosis in breast cancer cells resistant to estrogen deprivation. J Natl Cancer Inst 97: 1746-1759, 2005.

16. Gompel A, Somaï S, Chaouat M, Kazem A, Kloosterboer HJ, Beusman I, Forgez P, Mimoun M and Rostène W: Hormonal regulation of apoptosis in breast cells and tissues. Steroids 65: 593-598, 2000

17. Teixeira C, Reed JC and Pratt MA: Estrogen promotes chemotherapeutic drug resistance by a mechanism involving Bcl-2 proto-oncogene expression in human breast cancer cells. Cancer Res 55: 3902-3907, 1995.

18. Perillo B, Sasso A, Abbondanza C and Palumbo G: 17 $\beta$-estradiol inhibits apoptosis in MCF-7 cells, inducing $b c l-2$ expression via two estrogen-responsive elements present in the coding sequence. Mol Cell Biol 20: 2890-2901, 2000.

19. Rio MC and Chambon P: The pS2 gene, mRNA, and protein: a potential marker for human breast cancer. Cancer Cells 2: 269-274, 1990.

20. Bossenmeyer-Pourié C, Kannan R, Ribieras S, Wendling C, Stoll I, Thim L, Tomasetto C and Rio MC: The trefoil factor 1 participates in gastrointestinal cell differentiation by delaying G1-S phase transition and reducing apoptosis. J Cell Biol 157: 761-770, 2002.

21. Buron N, Guery L, Creuzot-Garcher C, Lafontaine PO, Bron A, Rio MC and Solary E: Trefoil factor TFF1-induced protection of conjunctival cells from apoptosis at premitochondrial and postmitochondrial levels. Invest Ophthalmol Vis Sci 49: 3790-3798, 2008.

22. Nunez AM, Jakowlev S, Briand JP, Gaire M, Krust A, Rio MC and Chambon P: Characterization of the estrogen-induced $\mathrm{pS} 2$ protein secreted by the human breast cancer cell line MCF-7. Endocrinology 121: 1759-1765, 1987.

23. Tomasetto $C$ and Rio MC: Pleiotropic effects of Trefoil Factor 1 deficiency. Cell Mol Life Sci 62: 2916-2920, 2005.

24. Ruchaud-Sparagano MH, Westley BR and May FE: The trefoil protein TFF1 is bound to MUC5AC in human gastric mucosa. Cell Mol Life Sci 61: 1946-1954, 2004.

25. Madsen J, Nielsen O, Tornøe I, Thim L and Holmskov U: Tissue localization of human trefoil factors 1,2 , and 3. J Histochem Cytochem 55: 505-513, 2007.

26. Thuwajit $P$, Chawengrattanachot $\mathrm{W}$, Thuwajit $\mathrm{C}$, Sripa B, May FE, Westley BR, Tepsiri NN, Paupairoj A and Chau-In S: Increased TFF1 trefoil protein expression in Opisthorchis viverrini-associated cholangiocarcinoma is important for invasive promotion. Hepatol Res 37: 295-304, 2007.

27. Prest SJ, May FE and Westley BR: The estrogen-regulated protein, TFF1, stimulates migration of human breast cancer cells. FASEB J 16: 592-594, 2002.

28. Soutto M, Belkhiri A, Piazuelo MB, Schneider BG, Peng D, Jiang A, Washington MK, Kokoye Y, Crowe SE, Zaika A, Correa P, Peek RM Jr and El-Rifai W: Loss of TFF1 is associated with activation of $\mathrm{NF}-\kappa \mathrm{B}$-mediated inflammation and gastric neoplasia in mice and humans. J Clin Invest 121: 1753-1767, 2011.

29. Gillesby BE and Zacharewski TR: pS2 (TFF1) levels in human breast cancer tumor samples: correlation with clinical and histological prognostic markers. Breast Cancer Res Treat 56: 253-265, 1999. 
30. Poulsom R, Hanby AM, Lalani EN, Hauser F, Hoffmann W and Stamp GW: Intestinal trefoil factor (TFF 3) and pS2 (TFF 1), but not spasmolytic polypeptide (TFF 2) mRNAs are co-expressed in normal, hyperplastic, and neoplastic human breast epithelium. J Pathol 183: 30-38, 1997.

31. Reshkin SJ, Tedone T, Correale M, Mangia A, Casavola V and Paradiso A: Association of pS2 (TFF1) release with breast tumour proliferative rate: in vitro and in vivo studies. Cell Prolif 32: 107-118, 1999.

32. Amiry N, Kong X, Muniraj N, Kannan N, Grandison PM, Lin J, Yang Y, Vouyovitch CM, Borges S, Perry JK, Mertani HC, Zhu T, Liu D and Lobie PE: Trefoil factor-1 (TFF1) enhances oncogenicity of mammary carcinoma cells. Endocrinology 150 4473-4483, 2009.

33. Buache E, Etique N, Alpy F, Stoll I, Muckensturm M, Reina-SanMartin B, Chenard MP, Tomasetto C and Rio MC: Deficiency in trefoil factor 1 (TFF1) increases tumorigenicity of human breast cancer cells and mammary tumor development in TFF1knockout mice. Oncogene 30: 3261-3273, 2011.

34. Miller WR: Clinical, pathological, proliferative and molecular responses associated with neoadjuvant aromatase inhibitor treatment in breast cancer. J Steroid Biochem Mol Biol 118: 273-276, 2010

35. Zhou L, Yan T, Jiang Y, Di G, Shen Z, Shao Z and Lu J: Prognostic and predictive value of TFF1 for adjuvant endocrine therapy in Chinese women with early ER positive breast cancer: comparing aromatase inhibitors with tamoxifen. Breast 20: 15-20, 2011.

36. Sinha AK: Colorimetric assay of catalase. Anal Biochem 47: 389-394, 1972.

37. Kudoh K, Ramanna M, Ravatn R, Elkahloun AG, Bittner ML, Meltzer PS, Trent JM, Dalton WS and Chin KV: Monitoring the expression profiles of doxorubicin-induced and doxorubicinresistant cancer cells by cDNA microarray. Cancer Res 60: 4161-4166, 2000.
38. Troester MA, Hoadley KA, Sorlie T, Herbert BS, BorresenDale AL, Lonning PE, Shay JW, Kaufmann WK and Perou CM: Cell-type-specific responses to chemotherapeutics in breast cancer. Cancer Res 64: 4218-4226, 2004.

39. Elmore LW, Di X, Dumur C, Holt SE and Gewirtz DA: Evasion of a single-step, chemotherapy-induced senescence in breast cancer cells: implications for treatment response. Clin Cancer Res 11: 2637-2643, 2005.

40. Mobley JA and Brueggemeier RW: Estrogen receptor-mediated regulation of oxidative stress and DNA damage in breast cancer. Carcinogenesis 25: 3-9, 2004

41. Sastre-Serra J, Valle A, Company MM, Garau I, Oliver J and Roca P: Estrogen down-regulates uncoupling proteins and increases oxidative stress in breast cancer. Free Radic Biol Med 48: 506-512, 2010.

42. O'Sullivan J, Whyte L, Drake J and Tenniswood M: Alterations in the post-translational modification and intracellular trafficking of clusterin in MCF-7 cells during apoptosis. Cell Death Differ 10: 914-927, 2003.

43. Won YS, Lee SJ, Yeo SG and Park DC: Effects of female sex hormones on clusterin expression and paclitaxel resistance in endometrial cancer cell lines. Int J Med Sci 9: 86-92, 2012.

44. Ikeda H, Taira N, Nogami T, Shien K, Okada M, Shien T, Doihara $\mathrm{H}$ and Miyoshi S: Combination treatment with fulvestrant and various cytotoxic agents (doxorubicin, paclitaxel, docetaxel, vinorelbine, and 5-fluorouracil) has a synergistic effect in estrogen receptor-positive breast cancer. Cancer Sci 102: 2038-2042, 2011

45. de Vincenzo R, Scambia G, Benedetti Panici P, Bonanno G, Ercoli A, Fattorossi A, Pernisco S, Isola G and Mancuso S: Chemosensitizing effect of tamoxifen and ICI 182,780 on parental and adriamycin-resistant MCF-7 human breast cancer cells. Ann NY Acad Sci 784: 517-520, 1996. 